\title{
EDUCAÇÃO INTEGRAL E ESCOLA EM TEMPO INTEGRAL: EM BUSCA DA FORMAÇÃO EMANCIPADORA
}

\author{
Maria Severina Gomes Melo Da Rocha, Universidade da Madeira - UMA \\ sevemrocha@hotmail.com \\ Henrique Miguel de Lima Silva, Universidade Federal da Paraíba - UFPB, \\ Henrque.miguel.91@gmail.com \\ Danielli Cristina de Lima Silva, Universidade Federal da Paraíba - UFPB \\ limaanacrisdani@gmail.com
}

\begin{abstract}
RESUMO
O presente trabalho é um recorte de uma pesquisa maior desenvolvida entre 2014 e 2016. Neste recorte, temos como objetivos estabelecer as diferenças entre a educação integral e a escola em tempo integral. Em seguida, discorremos sobre as contribuições da implantação de educação em tempo integral no Estado de Pernambuco - PE. Ressaltamos que este pioneirismo foi expandido para as escolas públicas brasileiras dos demais estados devido a sua grande valia em oferecer formação de qualidade, com princípios democráticos, críticos e humanistas e, sobretudo, com o compromisso social de transformar a realidade da sociedade. Compreende-se que para que a educação integral realmente ocorra, deve-se oportunizar aos indivíduos o desenvolvimento pleno de suas habilidades para que esse possa evoluir plenamente a partir da conjugação de suas potencialidades, fazer uso de seus conhecimentos, agir e tomar decisões dentro do mundo que o cerca. É oportunizar o desenvolvimento do ser indivíduo a partir do reconhecimento de si mesmo. Fundamentamos nossa pesquisa em Brasil (1996, 2000, 2013); Fino (2000, 2012); Freire (1996, 1978, 2006), Brandão (2002), Boruchovitch (2009), dentre outros, por refletirem diretamente sobre a formação integral e a diminuição das desigualdades sociais com base em uma educação crítica. Dessa maneira, esperamos que a formação emancipadora torna os sujeitos autores de sua própria história.
\end{abstract}

PALAVRAS-CHAVE: Educação Integral, Formação, Emancipação.

\section{NTEGRAL EDUCATION AND SCHOOL IN COMPREHENSIVE TIME: IN SEARCH OF THE EMANCIPATION FORMATION}

\section{ABSTRACT}

The present work is a cut of a major research developed between 2014 and 2016. In this section we aim to establish the differences between full and part-time schooling. Next, we discuss the contributions of the implementation of full time education in the State of 
Pernambuco - PE. We emphasize that this pioneerism has been expanded to Brazilian public schools in other states because of its great value in providing quality education, with democratic, critical and humanistic principles and, above all, with the social commitment to transform the reality of society. It is understood that for integral education to actually occur, individuals should be given the full development of their abilities so that they can fully evolve from the conjugation of their potentialities, make use of their knowledge, act and make decisions within the World around you. It is to promote the development of the individual being from the recognition of oneself. We base our research in Brazil (1996, 2000, 2013); Fino (2000, 2012); Freire (1996, 1978, 2006), Brandão (2002), Boruchovitch (2009), among others, for reflecting directly on integral education and the reduction of social inequalities based on critical education. In this way, we hope that emancipatory formation makes the subjects the authors of their own history.

KEY WORDS: Integral Education, Training, Emancipation.

\title{
EDUCACIÓN INTEGRAL Y ESCUELA EN TIEMPO INTEGRAL: EN BUSCA DE LA FORMACIÓN EMANCIPADORA
}

\begin{abstract}
RESUMEN
El presente trabajo es un recorte de una investigación mayor desarrollada entre 2014 y 2016. En este recorte, tenemos como objetivos establecer las diferencias entre la educación integral y la escuela a tiempo completo. A continuación, discordamos sobre las contribuciones de la implantación de educación a tiempo completo en el Estado de Pernambuco - PE. En el caso de las escuelas públicas brasileñas de los demás Estados, debido a su gran valor en ofrecer formación de calidad, con principios democráticos, críticos y humanistas y, sobre todo, con el compromiso social de transformar la realidad de la sociedad. Se entiende que para que la educación integral realmente ocurra, se debe oportunizar a los individuos el desarrollo pleno de sus habilidades para que éste pueda evolucionar plenamente a partir de la conjugación de sus potencialidades, hacer uso de sus conocimientos, actuar y tomar decisiones dentro del mismo, El mundo que lo rodea. Es oportuno el desarrollo del ser individual a partir del reconocimiento de sí mismo. Fundamentamos nuestra investigación en Brasil (1996, 2000, 2013); Fino (2000, 2012); (1996, 1978, 2006), Brandão (2002), Boruchovitch (2009), entre otros, por reflexionar directamente sobre la formación integral y la disminución de las desigualdades sociales basadas en una educación crítica. De esta manera, esperamos que la formación emancipadora hace a los sujetos autores de su propia historia.
\end{abstract}

PALABRAS CLAVE: Educación Integral, Formación, Emancipación.

\section{INTRODUÇÃO}


Diferenciar educação integral de escola em tempo integral se faz pertinente mediante o fato da prática do Estudo Supervisionado, objeto de estudo desta pesquisa, só ocorrer em escolas públicas estaduais de Pernambuco que utilizam o horário integral.

Por essência o tema educação integral é intensamente vasto. Quando esse termo é utilizado para institucionalizar o processo de formulação da escola surge certa confusão conceitual entre escola em tempo integral e educação integral.

Nessa perspectiva, a educação integral pressupõe um modelo de ensino que considera o estudante não apenas na dimensão cognitiva e sim numa esfera mais multidimensional do ser humano, aproximando-se do que Dewey, apud Westbrook, conceitua como educação " $o$ processo de reconstrução e reorganização da experiência, pelo qual the percebemos mais agudamente o sentido, e com isso nos habilitamos a melhor dirigir o curso de nossas experiências futuras." (WESTBROOK, 2010, p 37).

Ainda em se tratando da temática em questão, percebemos que a educação integral está fundamentada numa perspectiva mais humanística da educação, e para que esta de fato possa ser desenvolvida, é necessário também que "o educador se desenvolva plenamente, para que possa compreender e dar significado ao processo educativo, como condição para a ampliação do desenvolvimento humano de seus educandos." (GUARÁ, 2006, p 16).

Essa concepção de escola integral é embasada por propostas educacionais que visam reconhecer o aluno como um todo e não um ser fragmentado, utilizando diversas linguagens, em vários momentos e circunstâncias. $\mathrm{O}$ aluno desenvolve aspectos cognitivos, físicos, afetivos e sociais, inclusive não havendo uma hierarquia na sequência de desenvolvimento desses aspectos.

Já a educação em tempo integral, que está relacionada à ampliação do tempo de permanência do estudante na escola, aumento da jornada escolar, poderá possibilitar à valorização e aplicação de iniciativas educacionais extraescolares vinculadas à vida em sociedade.

De forma resumida, discorreremos sobre as contribuições do ensino em tempo integral como modelo de formação da autonomia tendo como base princípios democráticos e humanistas.

\section{DIFERENCIANDO EDUCAÇÃO INTEGRAL E ESCOLA EM TEMPO INTEGRAL}


Muitas vezes esse aumento no tempo de permanência na escola está diretamente relacionado à ideia de ocupar o tempo extra do aluno. A complexidade contemporânea da vida social transformou a estrutura familiar e mudou a rotina e necessidades das famílias. Hoje, em diversos lares os adultos trabalham o dia todo e precisam de um lugar seguro para deixarem seus filhos. Para estes, as escolas com o período integral são locais em que as crianças estão seguras e ainda podem desenvolver a aprendizagem e expandir seus conhecimentos.

Para Guará (2006) a concepção de educação integral

Agrega-se à ideia filosófica de homem integral, realçando a necessidade de desenvolvimento integral de suas faculdades cognitivas, afetivas, corporais e espirituais, resgatando, como tarefa prioritária da educação, a formação do homem, compreendido em sua totalidade. ( GUARÁ, 2006, p 16).

Nesse contexto, a escola em tempo integral apresenta-se como uma espécie de apoio as famílias em que os pais necessitam trabalhar e que não tem onde deixar seus filhos. Além disso, os pais se asseguram de que seus filhos estão livres da criminalidade das ruas. A preocupação com o conhecimento e desenvolvimento da aprendizagem dos alunos apresentase em muitos casos como algo secundário, uma consequência.

Sobre isso, Fino (2001) nos diz que:

\begin{abstract}
"O que sei é que a escola de hoje, depois de lhe terem sido cometidas funções que têm pouco a ver com o desenvolvimento das sociedades (servir de depósito onde as famílias colocam os filhos enquanto os pais trabalham ou de local onde os jovens vegetam o máximo possível de tempo antes de engrossarem a pressão dos que batem à porta das universidades ou do primeiro emprego), se encontra irremediavelmente ferida, e já nem é capaz de preparar para o presente, quanto mais para um futuro que nenhum visionário consegue antecipar." (FINO, 2001).
\end{abstract}

Por outro lado, sabe-se que muitas escolas que possuem jornada ampliada utilizam diversas estratégias pedagógicas para aproveitar a maior permanência do aluno na escola para assisti-lo mais integralmente, desenvolvendo atividades didáticas que fornecem ao aluno além de condições de ensino capaz de garantir aprendizagem ampla e diversificada, resgate da autoestima, oportunizando aos alunos alcançarem efetivamente a aprendizagem para que estes possam exercer o pleno exercício de sua cidadania. Estas escolas são reconhecidas como 'Escolas integrais em horário integral' e não apenas um 'depósito de crianças'. 
Como expõe Coelho (s/d) "com o tempo escolar ampliado, é possível pensar em uma educação que englobe formação e informação; que compreenda outras atividades - não apenas as pedagógicas - para a construção da cidadania partícipe e responsável". Nesse contexto, é possível buscar a articulação entre a escola em tempo integral para o real desenvolvimento de uma Educação Integral.

\section{A EDUCAÇÃO INTEGRAL NO BRASIL}

Nas últimas décadas, a Educação Integral tem ocupado lugar de destaque nos discursos sobre educação no Brasil. Fazendo surgir diversas iniciativas de implantação de modelos educacionais estruturados por propostas diferenciadas de escolas em tempo integral.

As primeiras concepções de educação integral no Brasil começaram a ser pensadas a partir do movimento Escola Nova, introduzido aqui no país no final do século XIX e início do século XX, que refletia a necessidade e importância de se reencontrar a verdadeira vocação da escola para a nova sociedade urbana que estava surgindo após a Primeira Guerra Mundial, bem como o advento da industrialização no país que fez surgir uma maior preocupação com a escola.

Assim, as rápidas transformações econômicas, políticas e sociais, ocasionadas pelo processo e crescimento urbano e econômico oriundas da industrialização crescente no Brasil na primeira metade do século XX, ocasionaram significativas mudanças no campo intelectual brasileiro.

Durante a década de 1930, surgiram no cenário educacional brasileiro algumas propostas direcionadas a uma formação integral e mais completa para os estudantes em que a educação fosse direcionada numa perspectiva que pudesse conciliar os conteúdos didáticos a outros aspectos da vida social. Entre essas, estiveram as do então líder do movimento Ação Integralista Brasileira, Plínio Salgado.

Segundo Monlevade (2010), Plinio Salgado "apresentou ao país a ideia e a necessidade da educação integral, apontando como bases a espiritualidade, o nacionalismo cívico e a disciplina". 
Em algumas de suas obras percebemos que para Plinio a educação aparece como um meio capaz de impulsionar a sociedade, a partir do desenvolvimento trazido pelo conhecimento e consequentemente aprofundamento dos fundamentos que a constituem.

Entretanto, um dos principais percussores na implementação das escolas em tempo integral no Brasil é o intelectual, educador e escritor Anísio Teixeira, um dos personagens centrais na história da educação brasileira. Anísio defendia um programa de educação que contemplasse as disciplinas básicas complementadas com artes individuais, desenho, música, dança educação física, saúde e alimentação. A partir da difusão dos pressupostos do movimento Escola Nova no Brasil, que tinha como objetivo a ênfase no desenvolvimento na capacidade de julgamento e não apenas a memorização.

O movimento escolanovismo de renovação do ensino, que teve suas bases na Europa e na América, difundiu-se aqui no Brasil na primeira metade do século XX sob importantes impactos de transformações econômicas, políticas e sociais. Esse movimento teve então entre outras benefícios para o Brasil a ampliação do pensamento liberal por difundir a importância da educação como elemento eficaz e base para a construção de uma sociedade democrática, capaz de tornar os cidadãos aptos a refletirem sobre a sociedade a que estava integrado, propondo assim novos rumos para o cenário educacional brasileiro naquele momento.

A partir das ideias difundidas por Anísio Teixeira, defendendo que o governo deveria assumir perante a sociedade o compromisso de oferecer ensino público gratuito e de qualidade como forma de inclusão, foram efetuadas algumas tentativas de implantação de escolas com jornada ampliada com propostas de educação integral, por meio de políticas públicas direcionadas para essa finalidade.

Na década de 1950, Anísio coloca seu modelo de ensino integral em prática num bairro pobre de Salvador, na Bahia, no Centro Educacional Carneiro Ribeiro, popularmente conhecido como 'Escola Parque'. Esta escola foi pioneira em oportunizar no Brasil, educação profissionalizante em tempo integral à populações mais carente.

No início da década de 1960, o então presidente da república Juscelino Kubitschek decide criar o Plano Humano de Brasília, reunindo alguns membros da elite de educadores brasileiros como: Anísio Teixeira, Darcy Ribeiro e Cyro dos Anjos, os quais foram encarregados de organizar um sistema educacional, que deveria ser o modelo para todo o 
Brasil. O modelo de Educação Integral para o nível educacional elementar desenvolvido pelo grupo de educadores foi inspirado no modelo educacional desenvolvido em Salvador por Anísio Teixeira, todavia mais evoluído, incluindo também a construção de escolas projetadas e equipadas para receber 30 mil estudantes. Entretanto, com a implantação do Governo Militar no Brasil, a partir de 1964 essas experiências de reorganização e popularização da escola foram extintas.

Nos anos de 1980, com o processo de redemocratização brasileira, o sistema escolar começa a se reorganizar, e nessa época são implementados no Estado do Rio de Janeiro, os Centros Integral Educação Pública, os CIEPs, concebidos pelo intelectual Darcy Ribeiro e inspirados na experiência de Anísio Teixeira da Escola Parque (Centro Educacional Carneiro Ribeiro) em Salvador -BA. Foram construídos 500 prédios para implantação de uma 'Escola Integral em horário integral' partindo do princípio da necessidade de se conceber uma educação mais completa aos educandos.

Os Cieps ofereciam além do currículo regular, estudos dirigidos, atividades culturais. Forneciam também refeições completas aos alunos, além de atendimento médico e odontológico. A prática didática do estudo dirigido utilizada nos CIEPs apresentavam algumas características semelhantes com a atual prática do Estudo Supervisionado utilizadas nas atuais escolas em tempo integral de Pernambuco. Nos CIEPs o Estudo Dirigido apresentavam:

[...] uma perspectiva bem mais ampla do que o estudo individualizado [...]. Engloba uma série bastante variada e diversificada de atividades, envolvendo todos os conteúdos explícitos e, muitas vezes, implícitos no currículo a serem realizados pelos alunos individualmente, em pequenos grupos e até, eventualmente, por todo o grupo em conjunto. Tais atividades têm por objetivo proporcionar aos alunos um momento para a realização, dentro da escola, de estudos e vivências pedagógicas dinâmicas que lhes proporcionem oportunidades de desenvolver a independência, a curiosidade e o gosto pelo estudo, pela pesquisa, pela reflexão e pela crítica. ( RIO DE JANEIRO/SEEDUC, 1991)

Percebemos que os objetivos da prática do Estudo Dirigido realizados nos CIEPs tinha como cunho principal o desenvolvimento da independência dos alunos como forma de alavancar outras habilidades nos jovens.

Do ponto de vista de alguns estudiosos, o principal motivo do fechamento dessas escolas integrais no Rio de Janeiro, foi a grande ênfase dada ao projeto como 'escola abrigo' voltada às camadas populares, que colocou a escola como solução e superação de diversos 
problemas sociais. A supervalorização das características preventiva da marginalidade fez a escola perder seu foco específico, que seria a formação do jovem numa esfera multidimencional.

Na década de 1990, o texto da Nova Lei de Diretrizes e Bases da Educação Nacional LDBN/1996 pronuncia de forma legal a ampliação progressiva da jornada escolar em direção ao tempo integral. Propondo a vinculação entre o trabalho escolar e a vida em sociedade, buscando a valorização de iniciativas educacionais extra-escolares.

Nessa década, os baixos índices observados na educação básica brasileira revelou a necessidade de melhorar a qualidade da educação no nosso país. Esse fator fez surgir à proposta de se implantar uma política de Educação Integral que proporcionasse a redução do fracasso escolar e possibilitasse às crianças e jovens novas perspectivas de desenvolvimento. Tornando-se, portanto um novo desafio para a educação pública no nosso país, mediante a complexidade que perpassava o sistema educacional em nível nacional.

A portaria Interministerial $n^{\circ}$ 17/2007 instituiu através do Decreto $n^{\circ} 7.083$, de 27 de janeiro de 2010, o Programa Mais Educação integrado as ações do Plano de Desenvolvimento da Educação (PDE), como uma estratégia do Governo Brasileiro para induzir a educação integral através da ampliação da jornada escolar e a organização curricular. Este programa visa contribuir para a diminuição das desigualdades educacionais bem como a valorização da diversidade cultural brasileira.

Nessa perspectiva, de acordo com o Decreto $\mathrm{n}^{\circ} 7.083 / 2010$.

“Os princípios da Educação Integral são traduzidos pela compreensão do direito de aprender como inerente ao direito à vida, à saúde, à liberdade, ao respeito, à dignidade e à convivência familiar e comunitária e como condição para o próprio desenvolvimento de uma sociedade republicana e democrática. Por meio da Educação Integral, reconhecem-se as múltiplas dimensões do ser humano e a peculiaridade do desenvolvimento de crianças, adolescentes e jovens.” (BRASIL/MEC 2012)

O Programa Mais Educação do Governo Federal Brasileiro, objetiva incentivar e apoiar projetos que visem ofertar ações socioeducativas oferecidas gratuitamente a crianças, adolescentes e jovens, considerando as seguintes orientações:

I. contemplar a ampliação do tempo e do espaço educativo de suas redes e escolas, pautada pela noção de formação integral e emancipadora;

II. promover a articulação, em âmbito local, entre as diversas políticas públicas que compõem o Programa e outras que atendam às mesmas finalidades; 
III. integrar as atividades ao projeto político-pedagógico das redes de ensino e escolas participantes;

IV. promover, em parceria com os Ministérios e Secretarias Federais participantes, a capacitação de gestores locais;

V. contribuir para a formação e o protagonismo de crianças, adolescentes e jovens;

VI. fomentar a participação das famílias e comunidades nas atividades desenvolvidas, bem como da sociedade civil, de organizações não-governamentais e esfera privada;

VII. fomentar a geração de conhecimentos e tecnologias sociais, inclusive por meio de parceria com universidades, centros de estudos e pesquisas, dentre outros;

VIII. desenvolver metodologias de planejamento das ações, que permitam a focalização da ação do Poder Público em territórios mais vulneráveis; e

IX. estimular a cooperação entre União, Estados, Distrito Federal e Municípios. (BRASIL/MEC 2012)

Atualmente a Educação Integral encontra-se presente na legislação educacional brasileira na Constituição Federal, nos artigos 205, 206 e 227; no Plano Nacional de Educação (Lei no 10.179/2001), na Lei de Diretrizes e Bases (Lei n 9394/1996), nos artigos 34 e 87; no Estatuto da Criança e do Adolescente (Lei n 9089/1990), no Fundo Nacional de Manutenção e Desenvolvimento do Ensino Básico e de Valorização do Magistério (Lei no 11.494/2007) e em alguns decretos.

\section{CONSIDERAÇÕES FINAIS}

É perceptível a necessidade de reestruturação do sistema educacional brasileiro e almejando responder aos grandes desafios presentes na educação nacional no século XXI, muitas práticas e concepções de educação integral vem sendo implantada no Brasil.

Nesse sentido, para que a educação integral realmente ocorra, deve-se oportunizar aos indivíduos o desenvolvimento pleno de suas habilidades para que esse possa evoluir plenamente a partir da conjugação de suas potencialidades, fazer uso de seus conhecimentos, agir e tomar decisões dentro do mundo que o cerca. É oportunizar o desenvolvimento do ser indivíduo a partir do reconhecimento de si mesmo.

No contexto do ensino integral, esperamos que estas escolas sejam uma realidade cotidiana em todas as escolas brasileiras, sobretudo nas públicas, oferecendo, dessa maneira condições para que as vozes marginalizadas sejam ouvidas e que todos tenham iguais condições de acesso e permanência em um ensino de qualidade. 


\section{REFERÊNCIAS}

ANDRÉ, Marli Eliza Dalmazo Afonso de: Etnografia da Prática Escolar. Campinas, SP. Papirus, 1995.

BARBOT, Marie José; CAMATARRI Geovani: Autonomia e Aprendizagem. A Inovação na Formação. Tradução: Emília Laura Seixas. Rés-Editora. 2001.

BERTRAND, Yves.; VALOIS, Paul: Paradgmas Educacionais. Escola e Sociedade. Horizontes Pedagógicos. Instituto Piaget. 1994. p. 67.

BOGDAN, Robert C.; BIKLEN, Sare Knopp: Investigação Qualitativa em Educação. Uma introdução a Teoria e aos Métodos. Tradução: Maria João, Sara Bahia e Telmo Mourinho. Porto Editora, 1994.

BORUCHOVITCH, Evely; BZUNECK; JOSÉ Aloyseo (orgs.). A Motivação do Aluno. Contribuições da Psicologia Contemporânea. $4^{\text {a }}$ Edição. Petropolis, RJ Editora Voves. 2009.

BRANDÃO, Zaia (Org): A Crise dos Paradigmas e Educação. $8^{a}$ Edição. São Paulo. Cortez. 2002.

BRASIL. LDB - Lei 9394/96 Lei de Diretrizes e Bases da Educação Nacional. Brasília: Corde, 1996.

Parâmetros Curriculares Nacionais para o Ensino Médio: Bases Legais, áreas das Linguagens, Códigos e suas Tecnologias , - Ciências da Natureza, Matemática e suas Tecnologias, - Ciências Humanas e suas Tecnologias . Brasília: MEC, 2000.

Manual Operacional de Educação Integral. MEC/Secretaria de Educação Básica.

Diretoria de Currículo e Educação Integra. Brasília-DF. 2012. Disponível em: $<$ http:portal.mec.gov.br.> Acesso: 13-08-2013.

DEMO, Pedro. Aprendizagem no Brasil: ainda muito por fazer. Porto Alegre: Mediação, 2004.

A Educação do Futuro e o Futuro da Educação. 2 ed. Campinas. Autores Associados. 2005.

DIAS Maria Carolina Nogueira; GUEDES, Patricia Mota. Modelo de Escola Charter: A Experiência de Pernambuco. Instituto Braudel. Fundação Itaú. s/d. 
FINO, C. N. Novas tecnologias, cognição e cultura: um estudo no primeiro ciclo do ensino básico (Doutoramento em Educação). 449f. Lisboa: Departamento de Educação da Faculdade de Ciências da Universidade de Lisboa. 2000. Disponível em: $<$ http://www.uma.pt/carlosfino/publicacoes/Tese_Carlos_Nogueira_Fino.pdf $>$ Acesso em: 29-Jul-2012.

Inovação pedagógica: significado e campo (de investigação). In: Actas do III Colóquio DCE-UMa. Funchal: Universidade da Madeira, 2007. Disponível em: http://www3.uma.pt/carlosfino/publicacoes/Inovacao_Pedadogica_Significado_\%20e_Camp o.pdf>. Acesso em: 10-Dez. 2012.

FREIRE, Paulo. Pedagogia do Oprimido. 17 ed. RJ: Paz e Terra, 1987. Pedagogia da Autonomia: Saberes Necessários à Prática Educativa. $11^{\mathrm{a}}$ edição. São Paulo: Ed. Paz e Terra, 1996.

Pedagogia da esperança: um reencontro com a Pedagogia do oprimido, 13. ed. São Paulo. Paz e Terra, 2006.

FRANCESCHINI, Adélia [et al]. Teoria e Prática da Pesquisa Aplicada. Rio de Janeiro. Elsevier Editora. 2012. Disponível em: http://books.google.com.br/books . Acesso em: 06-052013.

FULLAN Michel; HARGREAVES Andy. A Escola como Organização Aprendente. Buscando uma educação de qualidade. Tradução: Regina Garcez. $2^{a}$ edição. Artimed Editora. Porto Alegre, 2000.

MAGALHÃES, Marcos: A Juventude Brasileira ganha uma escola nona de ensino médio. Pernambuco cria, experimenta e aprova. - São Paulo: Albatroz: Loqüi, 2008.

MORAES, Maria Cândida: O Paradigma Educacional Emergente. 13 ${ }^{a}$ ed. Campinas. SP. Papirus. 2007.

MOREIRA, M.A. Aprendizagem significativa. Brasília. Unb. 1999 p 129.

. O Aluno Como Invenção. Trad. Daisy Vaz de Moraes. - Porto Alegre. Artmed, 2005.

SANTOS, Jùlio Cèsar Furtado: O Papel do Professor na Promoção da Aprendizagem Significativa. 2008. Disponível em: http://www.pedagogia.com.br/artigos/aprendizagemsig/ acesso: 08-06-2013. 
SANTOS, Júlio César Furtado dos Santos: Aprendizagem Significativa. Modalidades de aprendizagem e o papel do professor. Porto Alegre. Editora Mediação $3^{\text {a }}$ Edição. 2009.

SEBER, Maria da Glória: PIAGET O diálogo com acriança e o desenvolvimento do raciocínio. São Paulo. SP. Editora Scipione. 1997.

SERAFIM, Camila Aparecida; BARCELOS, Ana Maria Ferreira (2007): Dando os Primeiros Passos para a Aprendizagem Autônoma. Disponível em: unec.edu.br/ojs/index.php/unec02/article/viewFile/229/308. Acesso em: 10-06-2012. THURLER, Monica Gather: Inovar no Interior da Escola. Trad. Jeni Wolff. - Porto Alegre. Artmed Editora, 2001.

TOFFLER, A. O Choque do futuro. Tradução de: Eduardo Francisco Alves. $2^{\mathrm{a}}$ Ed. Editora Record. 1970.

WESTBROOK, Robert B.; TEIXEIRA, Anísio: Jonh Dewey. Coleção Educadores do MEC. Tradução e org. José Eustáquio Romão e Verone Lane Rodrigues. Editora Massangana. Recife. 2010. 